\title{
The Strategic Approach of Total Quality and Their Effects on the Public Organization
}

\author{
Luminita Gabriela Popescu \\ National School of Political Studies and Public Administration
}

Romania

\section{Introduction}

The main objective of this chapter is to emphasize the main effects produced, in an organization, by the integration of total quality strategy within the general strategy of the organization. For this integration to be possible it is mandatory to construct an adequate context. In the second part of the chapter, the transfer achieved through the integration of quality strategy within the organization's strategy is undertaken.

The research methodology that consists of the institutional analysis (Meyer and Rowan, 1977; DiMaggio and Powell, 1983; North, 1990) is a type of social science research that seeks to reveal the effects on formal policies, informal norms and interpretations of the practices associated representative of a particular area on the actual scope.

The organizations analysis highlights ways in which different social institutions - legal norms, regulations, procedures and their associated meanings - and propose working material and symbolic incentives (reputation, trust, accreditation) and thereby generate configurations of processes, strategies and practices at the organizational level.

Carrying on, we will present the main steps contained by the two parts of the chapter

\section{The constitutive context of quality strategic approach}

Under the pressure of the citizens whose exigencies are becoming more and more sophisticated; of the new management approaches that imply, for example, the abandonment of the Management by Objective and the endorsement of the Management by Results; of domestic political forces and due to constrains from the global socialpolitical forces, the need for reform and innovation in the public sector is more and more obvious.

In the bureaucratic hierarchy, activities take place according to general rules and norms. The main objective of the structures and the managerial control instruments is ensuring the conformity with the prior rules and norms. In such a system, the improvement of the efficiency and the effectiveness of the processes involve endorsement of several legislative alterations. 


\subsection{Meta-organization}

In this new context "quality approach in public sector is not only a technical measurement and implementation issue. It is also a political problem where changes in quality are connected to government activity and, in the end, to society activity"1

This implies that public organizations evolve²:

a. from a closed, self-centered service provider to an open networking organization which public trust in society through transparent process and accountability and trough democratic dialogue;

b. from an internal (resources and activities) focus to external (output and outcome) focus;

c. from a classical design-decision-production-evaluation cycle to an involvement of stakeholders in general, and citizen (as customers) in particular at each and every stage.

Achievement means giving up old paradigms and acceptance of some innovative approaches in which services beneficiaries / users are, at the same time, co-participants in the innovation of the public service they benefit from. In other words, the development of a new type of relationship between public services providers and their beneficiaries / users is necessary.

Moreover, the new managerial approaches related to quality strategic approach (Management Based on Results) impose closer attention paid to results.

Focusing on results expresses the need for the creation of a strategic vision of the expected finality, vision which exceeds the orders of the organization and which takes into consideration, on the one hand the fructification of the positive influences from external factors, and on the other hand reduction (elimination) of threats coming from them.

Consequently, the innovation of public services according to these coordinates becomes possible only when a meta-organization which the organization of public services, beneficiaries / users of public service interested in outputs and other categories of stakeholders interested especially in results be part of, can be achieved The metaorganization, as a flexible network-type structure, is built in such a way that it contains both the organization that provides the service and the actors that surround it. The latter are either customers/users of the service or representatives of the community's interests. In figure 1 the meta-organization is represented for a particular case of a social service.

The actors involved are users/customers of the provided public service, representatives of the community's interests observing the exigencies necessary to the provision of the service and other categories of stakeholders, as well.

We think that the presence of International/European Bodies in the structure of a metaorganization is a gain because the former can be used as "bases of best practice", useful for improving the performances of the provided service.

1 C. , Politt and G., Bouckaert, Quality Improvement in European Public Services, SAGE Publication Ltd. London, 1995. p.12.

2 C., Pollitt, G.,.Bouckaert, E.,Loffler, Making Quality Sustainable: Co-Design, Co-Decide, Co-Produce, and Co-Evaluate, The 4QC Conference, Tampere, 2006., pp.5-6. 


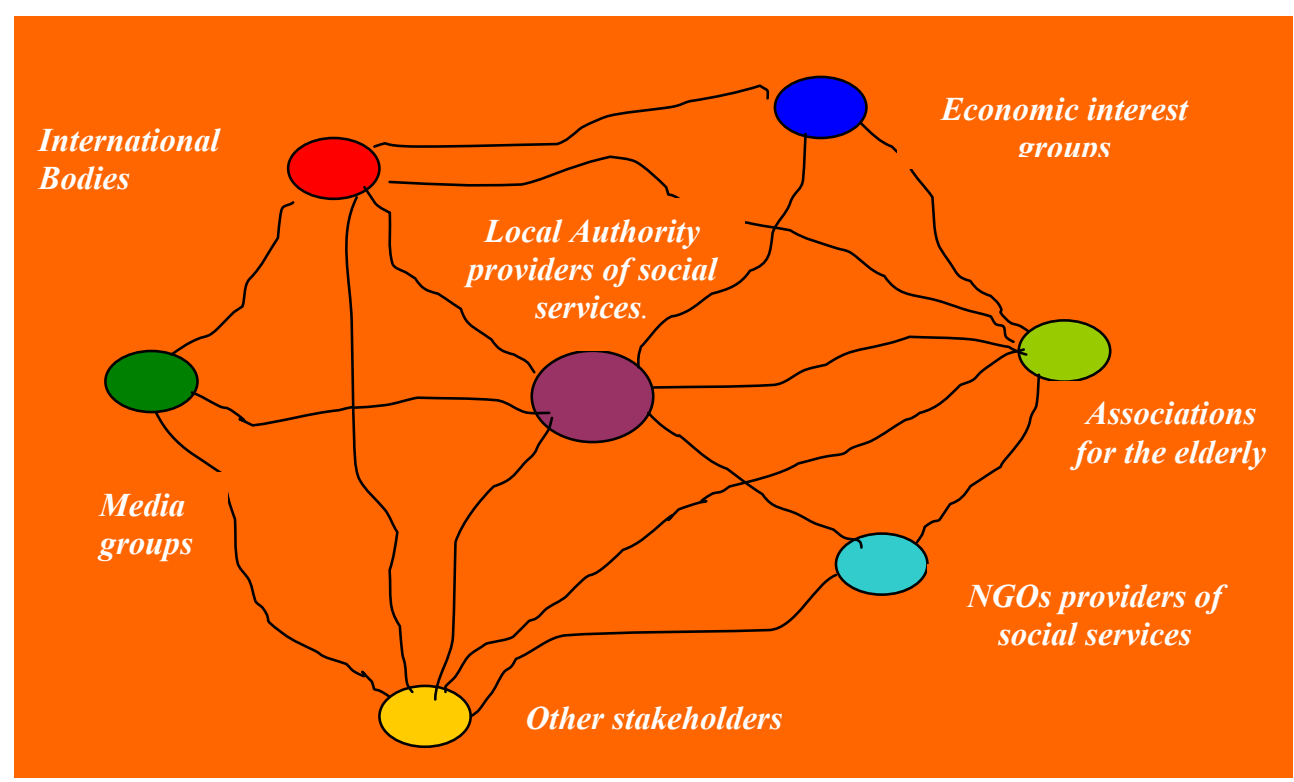

Fig. 1. The Model of Meta-organization- The case of the public service for social protection at local level (Adapted after L.G.Popescu, (2005), Public Policy, Ed.Economica, Bucharest, p.135)

This construction represents a potential solution based on co-operation between all the actors of the meta-organization, aimed at creating innovatory public services.

Cooperative solutions are required, not only in the form of co-operation between governments but also through co-operation between governments (centrally, regionally, locally), civil society association and other stakeholders such as media and business (C., Pollitt, G.,.Bouckaert, E., Loffler, 2006, p.8).

As a first conclusion, the configuration of the constitutive context of public services innovation through the strategic approach to quality implies the need for a new strategic and innovative thinking in the relationship between the central administration and the local and regional administrative organizations, between administrations and citizens belonging to local and regional communities, between administrations and different groups of stakeholders.

Secondly, there is an urgent demand to make the central and local administration structures more efficient (for them to become compatible with the flexible structure of the metaorganization) and to limit the decision-making capacity of the administrations by involving citizens and interest groups representative for the community in the decision-making process.

Pragmatically, the achievement of such a structure implies overcoming a variety of challenges. On the one hand, are the members of the community aware of the importance of their commitment? Are they truly motivated to take part in such a structure? On the other hand, how prepared are political representatives and public authorities to accept cooperation with different categories of stakeholders? 
First of all, the lack of a quality culture with all the actors of the meta-organization (respectively the quality culture of the members of the community) is one of the major difficulties to overcome in reaching the success of this construction. The responsibility of both political and public authorities to enable this structure to become functional must be focused on the development of this type of community culture. Only when community members become aware of the benefits of the innovation of public services through quality and are willing to commit themselves in different forms, the meta-organization will be substantial.

In conclusion, achieving the quality strategy in public services as seen by this paper is impossible without an informed and active community truly involved in the innovation of public services. Mutually, the members of the community cannot reach the level of quality culture that implies commitment and attendance if the responsible agents at the central, regional or local level do not focus their efforts towards both stimulating the members of the community to commit themselves to innovating public services and revealing the advantages of "listening to the customer's voice" rather than "listening to the hierarchy voice" (L.G. Popescu 2002, p.56).

\subsection{A new projection of the quality circle}

In these circumstances the traditional, purely legal relationship between consumer and provider is replaced by a creative cooperation and collaboration between the actors of the meta-organization.

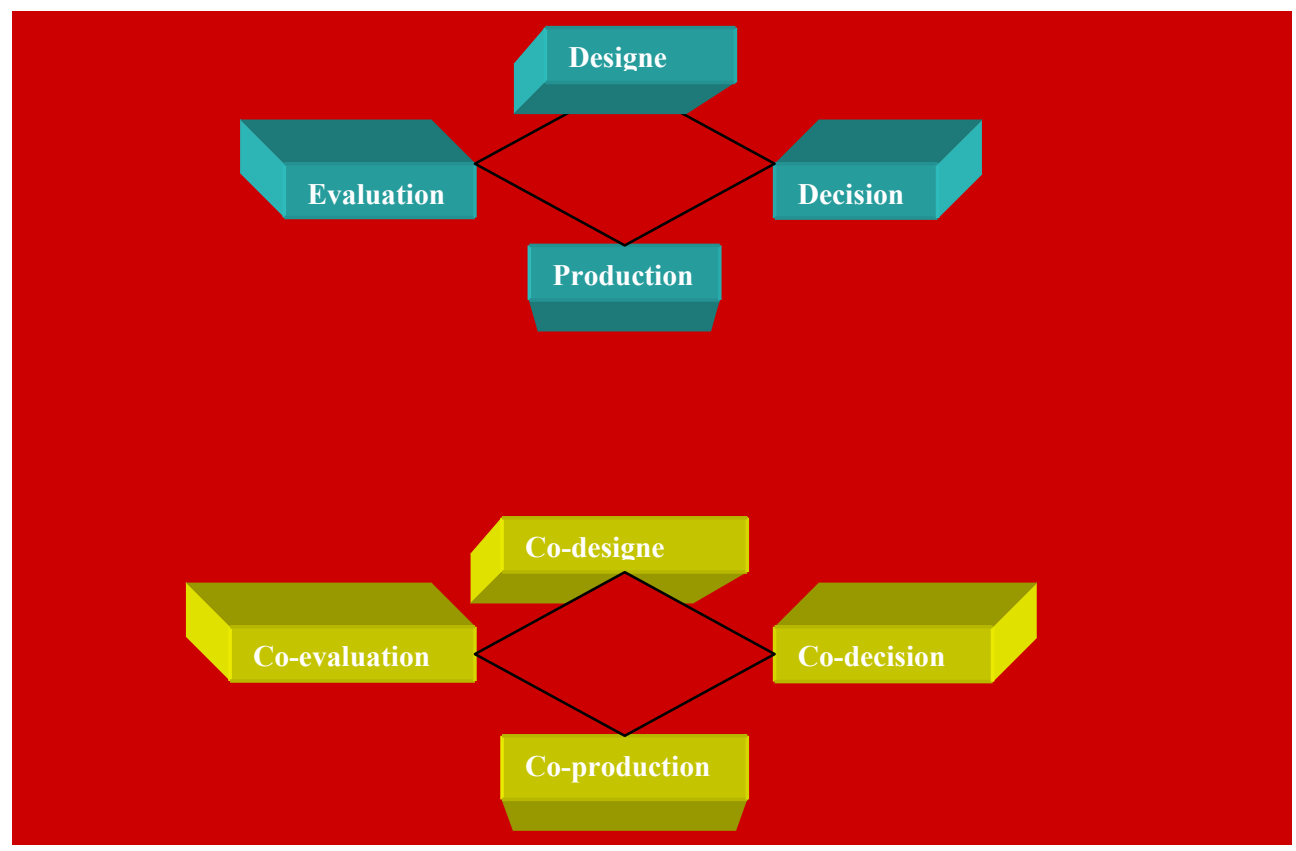

Fig. 2. The shift to co-design, co-decision, co-production and co-evaluation Source: C., Pollitt, G., Bouckaert, E.,Loffler, (2006), Making Quality Sustainable: Co- Design, Co-Decide, Co-Produce, and Co-Evaluate, Report of The 4QC Conference, Tampere, p. 7. 
Moreover, inside the meta-organization, the contradictions between the concepts "consumer" and "provider" and the cooperation and creative dialogue relationships between actors should be revealed.

In figure 2, one can see the result of this deep change determined by the principles on which the new type of relationship develops; from the traditional type where the consumer was "stopped at the gate of the organization" to the new one, where he becomes co-participant throughout the quality cycle: co-design, co-decision, co-produce and co-evaluation (C., Pollitt, G., Bouckaert, E., Loffler, 2006, p.7).

\section{Quality strategic approach}

From the meta-organizational point of view, the Strategic Approach to Quality is formulated based on a macro-vision of itself and it is the ability to simultaneously conduct changes of the consisting systems.

According to our theory, which we will try to demonstrate here, the Strategic Approach to Quality materializes in a complex change oriented towards four dimensions: re-defining the potential meta-organization, re-structuring the meta-organization, re-vitalizing the portfolio of the meta- organization and reinventing the mentalities (see fig.3).

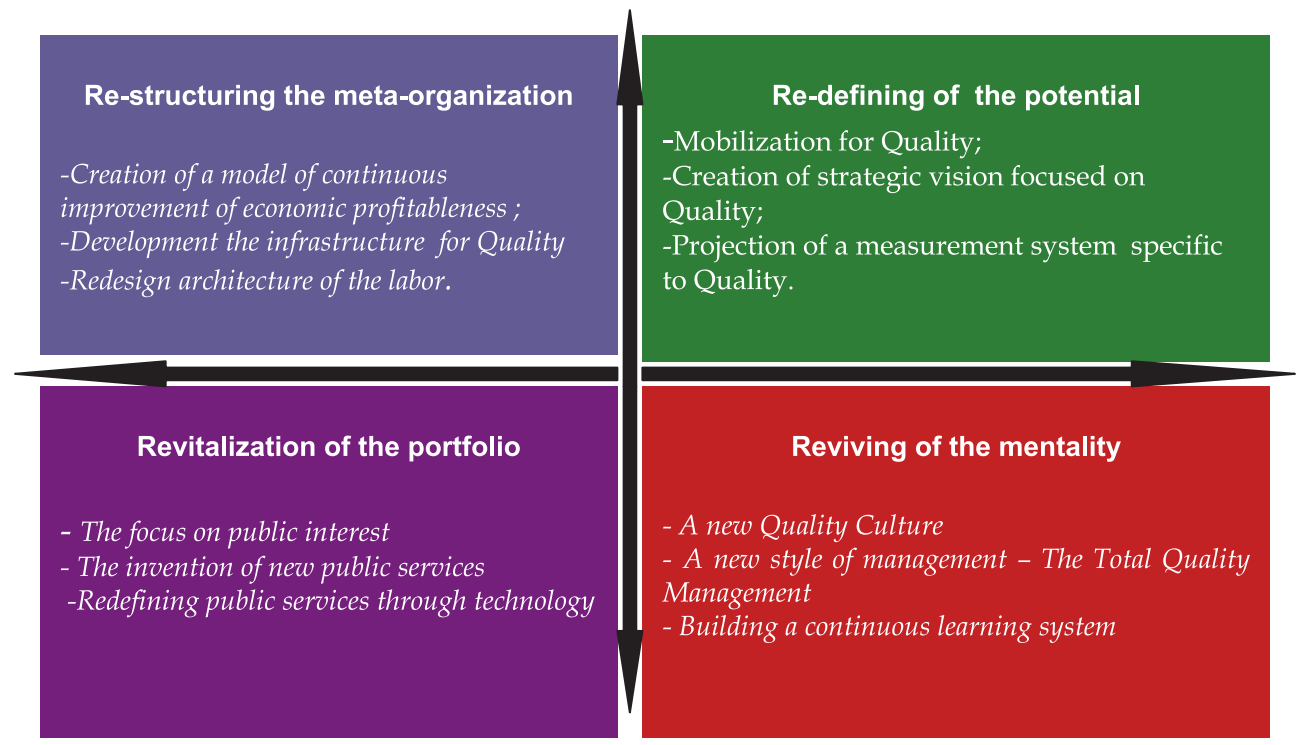

Fig. 3. The stages of Quality strategic approach in public services

\subsection{Re-defining the potential of the meta-organization}

This dimension implies giving up old patterns and restricting thinking concepts, and accepting new patterns and visions of what the provided public service is and what it could become.

The contents of this transformation include: achievement of mobilization for Quality, creation of a strategic vision focused on Quality and projection of a measurement system for 
Quality. In the centre of this transformation there is the development of the energies necessary to the innovation of the service, in other words the mobilization of intelligence and motivation both at the level of the external actors and the internal ones in order to innovate the public service.

\subsubsection{Mobilization for quality}

Analyses and studies conducted in several organizations in the Romanian public sector have led us to the conclusion that the difficulties occurred during the application of the Quality strategic approach are mainly results of the maintenance of the traditional system where the relationships are essentially bureaucratic and hierarchical.

The political leaders determine what service has to be provided, on what terms and to whom, and bureaucrats and professionals subsequently organize and deliver that service. The role of the citizens is mainly passive. In such a system, completely inadequate for the present-day needs, activities take part without paying attention to the effects on the community / society as a whole. The conditions or quality mobilization to become operational are:

- The development of an open communication system mainly characterized by the free circulation of formal and informal messages within the meta-organization. Messages are sent in every direction: on the vertical, in both ways and on the horizontal, without any constrains or inhibitions imposed by the chain of command of the hierarchy in the organization;

- Participation, meaning the degree in which the internal and external actors involve themselves in the cycle of the quality: design, decision, production, and evaluation.

Applying these tenets requires managerial efforts oriented firstly towards acknowledgement of the importance of the relationship between the actors and secondly, towards the provision of resources and information, support and freedom of initiative necessary to develop this relationship satisfactorily.

Contrary, there will be negative effects both on the external actors whose requirements have not been met, and on the internal factors which will be frustrated and de-motivated by the lack of finality in their actions.

In conclusion, orientation towards the external factors is reflected through the managerial availability to satisfy the internal actors' requirements because only when their needs are satisfied they can focus on other actors in the meta-organization and not on their own necessities.

\subsubsection{Creation of the strategic vision}

Being a reflection of the managerial philosophy of the organizational action mode of public services as a whole, this vision represents both a challenge to exceed the status quo and the essence of the most significant meta-organizational aspirations in a new raison d'être.

The development of the strategic vision focused on Quality offers the opportunity for the management to commit itself to an aggressive strategic approach, but to maintain enough realism to be a permanent source of concentration and motivation.

The organizations of public services are directly influenced by the innovative ability of the services provided, and the approach which reflects the strategic essence of Quality is a major support not only in the articulation of the strategic intention, but also in motivating through 
means specific to Quality: involvement of the strategic management, continuous improvement, innovation and reengineering at the level of the meta-organization.

\subsubsection{Projection of a system of quality measurement}

The confirmation of the achievement of the strategic vision of Quality is possible only after the building of a system of continuous measurement, gathering and reporting of actions referring to the quality of exits and results. Focus on Quality in the public sector can be situated at the three levels: the micro, the meso and the macro level of the society.

Micro-quality is an internal quality concept that applies to the interrelationships of the top, middle and base of an organization.

Meso-quality is an external concept that applies to the relationships between producer and consumer, or supply and demand, or provider and user.

Macro-quality is a generic system concept that applies to the relationships between a public, service and the citizenry, and to the relationship between the state and civil society (C. Politt and G. Bouckaert, 1995, p.14-15).

The construction of the system must be oriented to measure:

1. Meso-quality-, i.e. satisfying users / customers exigencies;

2. Macro-quality-, i.e. gain for society / community;

3. Micro-quality- i.e. interventions in the organization, among which there are:

i. the quality of processes, their efficiency and effectiveness;

ii. the expectations and satisfaction of the members of the organization.

The system of quality measurement was projected in the stage that contains a series of performance indicators, performance through which one can determine on a value scale up to which level public interests have been satisfied and at what expense. The performance of a public organization is determined according to the way human, material, informational and financial resources are used to achieve the objectives established at the level of service beneficiaries' expectations.

The process of measuring the performance results in the public sector is, most specialists admit, an especially difficult one for several reasons:

- multitude and diversity of stakeholders in a public institution: current and potential customers, electors, elected representatives, non-profit organizations, professional groups, unions, public managers, the government etc;

- differences in evaluation and perception of performance among stakeholders;

- non-existence of a competitive environment where certain services are offered from the position of monopoly some public institutions and administrative authorities have on those services;

- $\quad$ nature of the public service offered;

- complexity of the social-political environment which generates a series of risks with direct influence on performance achievement; and

- $\quad$ influence of political values. 
The confirmation of achievement of the strategic vision of Quality is possible only after a system of continuous measurement, gathering and reporting of actions referring to the quality of exits and results is built. As you can see in figure 4, the construction of the system must be oriented to measure:

1. short term results, i.e. satisfying users / customers exigencies;

2. long term results, i.e. gain for society / community;

3. the quality of interventions in the organization, among which there are:

i. the quality of processes, their efficiency and effectiveness;

ii. the expectations and satisfaction of the members of the organization.
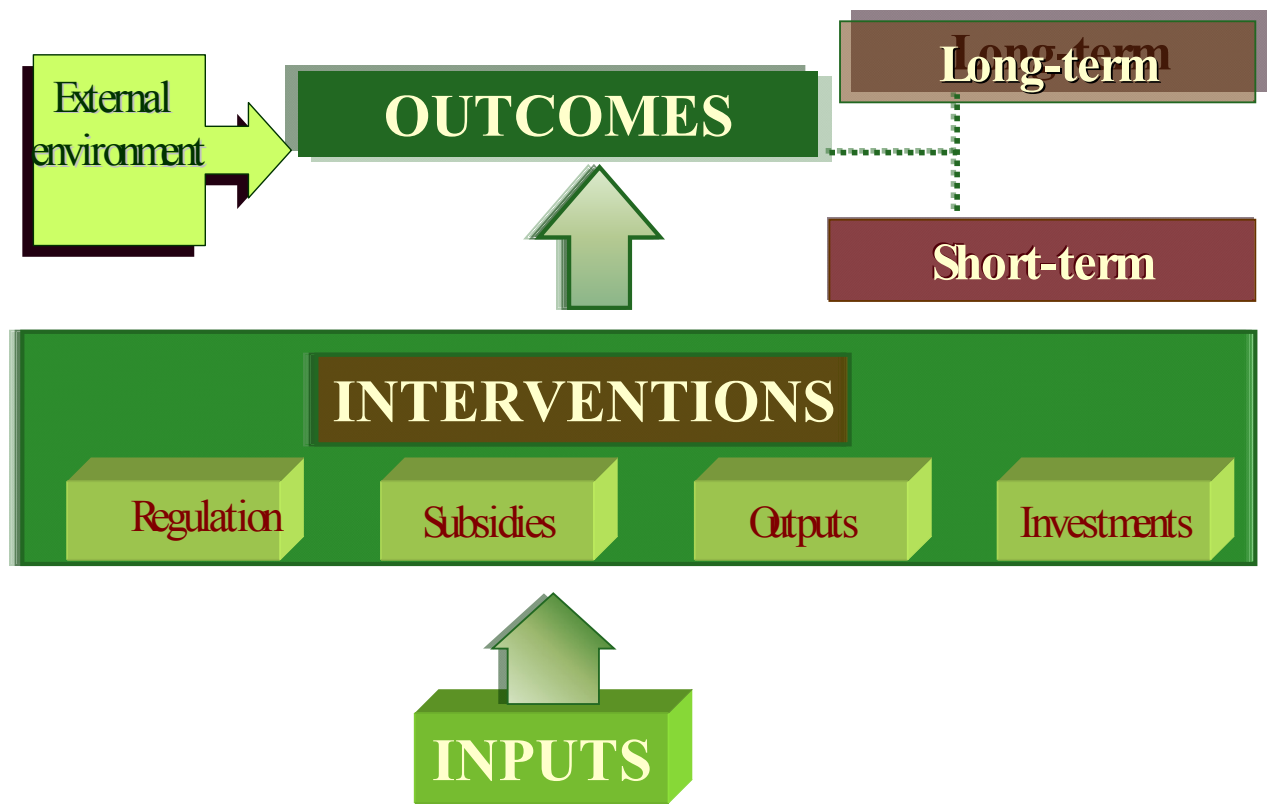

Fig. 4. The chain of the results

The process of measuring the performance results in the public sector is, most specialists admit, an especially difficult one for several reasons:

- multitude and diversity of stakeholders in a public organization: current and potential customers, electors, elected representatives, non-profit organiations, professional groups, unions, public managers, the government etc;

- differences in evaluation and perception of performance among stakeholders;

- non-existance of a competitive environment where certain services are offered from the position of monopoly some public institutions and administrative authorities have on those services;

- $\quad$ nature of the public service offered;

- complexity of the social-political environment which generates a series of risks with direct influence on performance achievement;

- $\quad$ influence of political values. 
Starting from these ground reasons, in 1994 Stewart and Walsh considered that the evaluation of the performance in the public sector is based on the political argument that defines the coordinates for the identification of performance criteria.

The steps towards performance measuring are the following:

- $\quad$ Defining the expected results (ER);

- Selecting the performance indicators that measure progress in achieving the results;

- Determining final and intermediary performance targes;

- Developing a plan to measure performance using ER indicators;

- Developing tools to gather data referring to each indicator;

- Continuing to gather data and comparing them to the targets previously determined.

Indicators used in defining the expected results (ER) are characterized by:

- Unit of analysis;

- Existing baseline information;

- Useful benchmarks for comparison;

- Expected perceptions or judgments of progress by stakeholders;

- Detailed description of expected conditions or situations to be observed.

Measuring the satisfaction of the metaorganizational actors

From the perspective of external actors, innovation of the public service through quality implies satisfaction of the indicators considered representative for defining the expected results ${ }^{3}$

The fact that external consumers' satisfaction is expressed according to the quality of products and services is the result of a significant number of elements determined by both the product itself $(\mathrm{Q})$ and the circumstances it was delivered in (VALITYM) and thus, we consider that the measure of the external consumers' satisfaction (SCE) can be expressed by an algebraic sum of the measure of the satisfaction brought to consumers by each element of the set $\{$ QVALITYM $\}$ according to relation (1.1):

$$
S C E=\sum_{i=1}^{8} S i \quad i \in\{\text { QVALITYM }\}
$$

where $S i$ is the measure of the consumer's satisfaction brought by the quality of element $i$.

According to this relation, SCE is maximum if each $S_{Q} \ldots S_{M}$ is maximum. Practically, problems should be approached differently because the importance of each element of $\{$ QVALITYM $\}$ varies according to each consumer or segment of consumers.

In this hypothesis, external consumer satisfaction must be expressed according to:

1. Satisfaction $(\mathrm{Si})$ of the quality achieved by each element of the set $\{$ QVALITYM\};

2. Importance $W_{i}$ given by the consumer to each element of the set \{QVALITYM\}.

Thus, relation (1.1) becomes relation (1.2):

${ }^{3}$ J.Kelada defines quality through a number of seven indicators : Conformity, Volume, Administrative Procedures, Location, Interrelations, Image, Time Yield (QVALITY). L.G.Popescu adds environment (M) to those defined by J.Kelada. 


$$
\text { To point out } S C E=\sum_{i=1}^{8} W i S i \quad i \in\{\text { QVALITYM }\}
$$

The importance given by consumers to each $W_{\mathrm{i}}, \mathrm{i} \in\{$ QVALITYM $\}$, we score it from 0 to 100 with the restriction:

$$
\sum_{i=1}^{8} W i=100 \% ; \quad i \in\{\text { QVALITYM }\}
$$

In figure 5 one can see the importance given by the external actors to each indicator that defines the satisfaction of the public interest.

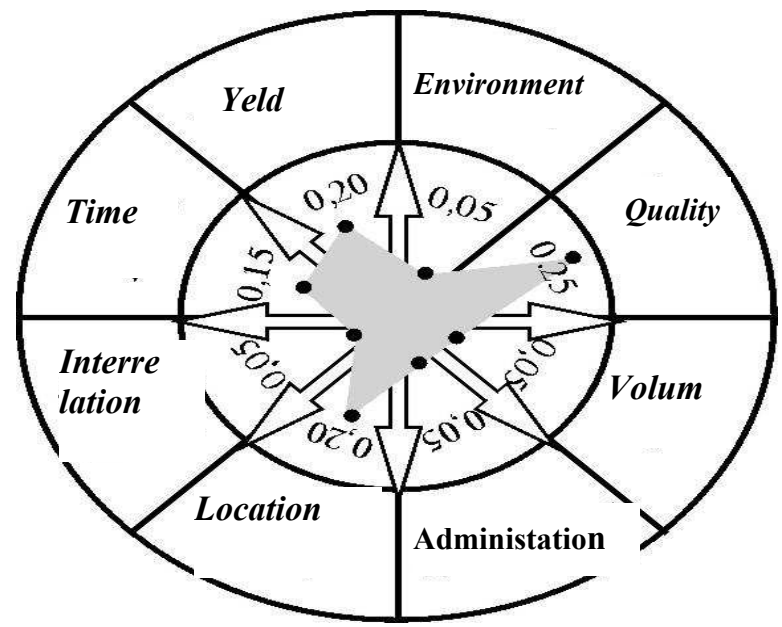

Fig. 5. Illustration of public interest satisfaction according to metaorganizational actors' assessment

The zone in the centre of the figure represents the way the actors of the analysed metaorganization relate to each of the elements of the set QVALITYM, theoretically being considered as having the same importance (the 8 sectors in the circle are identical).

From the analysis of this figure we can conclude that the most important dimension is Quality, it has 25\%. Economic efficiency and Delivery venue are the next important dimensions, they have 20\%, while delivery Time has 15\% and Volume 10\%. Consumerprovider relationships and Environment have the same procentage, $5 \%$.

If this exercise is done again on a different type of service, the dimensions in figure 5 will be completely different, being determined by the preferences of the actors of the metaorganization.

Measuring the satisfactionof the internal actors

The relationships between the internal and external actors are especially important in the philosophy of Quality Management having a great impact on the satisfaction of the public interest. Although, when we talk about quality there is an instant tendency to refer to the quality of the service, for Quality Management the emphasis on quality of the people is 
substantial. Practice proves that organizations where public managers give importance to the quality of the human relationships have already completed half the way to the achievement of the quality strategic approach. That is why the measurement of their satisfaction is mandatory.

\section{Process measurement}

The system of Quality Measurement involves controlling both process results (the so-called final inspection) and control points in the on-going process (the so-called interphasic inspection).

Generally, the achievement of a coherent Measurement System which comprises both types of measurement is difficult. Its difficulty is not to determine a model for the Measurement System, but to mobilize the members of the organization to involve in identifying and measuring in the decisive points, both final and interphasic Starting from these reasons, we can consider that the evaluation of the performance in the public sector is based on the political argument that defines the coordinates for the identification of performance criteria.

\subsection{Re-structuring the meta-organization}

Participation of the actors contained by the meta-organization to the decision making process regarding restructuring of the organization gives it more legitimacy and increases their satisfaction, as well. The details of restructuring are presented in the following lines.

Participation of the actors contained by the metaorganization to the decision-making process regarding restructuring of the organization gives it more legitimacy and increases their satisfaction, as well. The details of restructuring are presented in the following lines.

\subsubsection{Creation of a model of continuous improvement of economic profitableness}

In the context of limitation of other economic models, there are questions such as: Which is the real relationship between quality and profitableness? What actions need to be taken to link the process of quality improvement to profitableness? The answers to these questions include decisions referring to: where and how improvement efforts must be focused, what products / services must be sold, what prices must be charged and when.

The model we suggest brings up again the paradigm associated to the present economic concepts and, at the same time, it offers a logical solution to build an infrastructure that favours financial performance. This model changes the approch towards increasing the viability of the business and completes the present environment from a global perspective of profit problems.

The development of the model is focused on making the business profitable, i.e. optimizing the two factors: profitableness and assets; which are part of a profitable business.

Profitableness is the profit limit achieved according to the turnover. Profit expresses the economic value of the business on the market, respectively its quality to create supplementary wealth. In a broad interpretation of the definition of profitableness, we can say that it is not measured only by the presence of profit, but alsoby the quality of the business to provide customers with products / services they need and the competition cannot offer.

The financial health of a business implies placing under discussion the second factor of the relationship, capital rotation. The business is more performant when it mobilizes less capital 
to achieve the same turnover and reduces the time between expenses and cashings. In other words, the faster the answer to the market is, the higher the probability of optimizing the business profit is.

Capital rotation is the speed at which the business converts expenses into turnover, measures the speed at which the business is able to satisfy the market. This rotation depends on the cycle of development, production, and marketing and on the flexibility of the business reaction speed. Thus, the relationship of profitableness although it seems to be a purely financial on, actually is the measure of the quality of the organizational adaptation to the market.

In conclusion, the economic model suggested above intends to accurately record the customer's voice regarding the added value and the speed at which this is brought onto the market.

The projection of this model implies four stages with the following content:

a. analysis of the profitableness of the product / service beginning with the strategic placement;

b. analysis of the present profitableness of the product / service;

c. identification of constraints; the importance of identifying these constraints and their impact on the strategic objectives lies in determining the directions of improvement efforts. Moreover, the profitableness of the organization would be maximum, at least theoretically if one knows and masters these constraints and limitations. According to their origin, there are several categories of constraints:

i. behavioural;

ii. managerial;

iii. production capacities;

iv. logistics;

v. conditions outside the organization;

vi. mentality regarding costs.

d. allocation of resources to different activities ( $A B C / A B M)$

Creation and reprojection of the allocation of resources system implies focusing on the targets of the business processwithin the chain of value. Each process is divided into component activities to which the corresponding costs are added in the $A B C$ technique (Activities Based on Costs). This technique provides accurate information about the improvement of results and elimination of difficulties. According to this approach resources are allocated to the activities leading to the product achievement, not to the product, as it happens in the traditional approach. Essential to establishing the real costs of projection, execution and distribution of a product, $\mathrm{ABC} / \mathrm{ABM}$ techniques (Activity Based on Costs/Activity Based on Management) are a useful tool in Quality Management.

Through the association between $\mathrm{ABC} / \mathrm{ABM}$ techniques and certain practices specific to Quality Management, the process of establishing the total cost of a product goes through the following stages":

a. identification of all activities which, directly or indirrectly, contribute to the achievement of the product is characteristic to technique $\mathrm{ABC}$.

b. selection of activities according to their contribution to the achievement of the product and which expresses technique ABM logics. And (according to Law Pareto) as about

\footnotetext{
${ }^{4}$ Kelada J. op. cit. p. 377
} 
$20 \%$ of all activities create $80 \%$ of the value of the product, they must be paid the greatest attention.

c. gathering the activities inside the process of achieving the product / service. Through the practice specific to Quality Management of creation of horizontal teams, they succeed in integrating the activities and the functions into a unitary process.

d. global integration by linking the process of achieving the product / service to the internal actors, external ones and stakeholders composing the metaorganization; which reflects the integration of the strategy of Quality at the level of this structure.

\subsubsection{Reprojection of work architecture}

Public organizations where direct quality costs exceed $15-20 \%$ of the annual turnover are considered by O.Gelinier ${ }^{5}$ ghost factories. Under this name a duality specific to nonperformant companies is hiding: on the one hand, the competitive factory which produces the economic value, and on the other hand, the ghost factory which produces non-value at the expense of the competitive factory.

The implementation of a reduction programme for non-quality based on the principle of zero-faults (zero faults, breakdowns, delays, stocks and bureaucracy) is the Quality strategic alternative to eliminate the ghost factory and thus, to increase productivuty and production capacity.

The decision of implementation of a reduction programme for non-quality took into account the ghost sub-activities that existed in different sectors of the company and was firstly directed towards the areas with the biggest loss.

Simplification of individual processes through reduction and elimination of ghost subactivities contributes to the reduction of the possibilities for errors to occur and the reduction of errors determines the reduction of the number of repetitive stages in a process, and so on.

According to the previous statements, the methodology of achieving a new work configuration includes the alternative of continuous improvement of the existing process. In case this alternative becomes either impossible or achievable or too expensive, the alternative is the implementation of an improved project of the process, through reengineering ${ }^{6}$. In this respect, we underline that both alternatives are components of the improvement process specific to innovation through quality.

Reconfiguration of the entire network which will integrate the objectives and measurement systems in a real production process, is a long term change for which achievement managerial efforts, costs and resources are involved. A very good example is just in time (JIT), which is a rather recent managerial approach focused on the elimination of loss at the level of the entire organization based on the reduction of manufacturing times, stocks and waiting times. Achievement of the proposed objectives is possible only if the management promotes the philosophy just in time at the level of the entire metaorganization.

${ }^{5}$ Gelinier, O. (1990) ,Stratégie de lentreprise et motivation des hommes, Ed. Hommes et Techniques, Paris, p.112.

${ }^{6}$ M., Hammer, J.,Champy (1996) Reeingineering of Enterprise, ed. Tehnică, Bucureşti, p.25. 


\subsubsection{The development of the infrastructure for Quality}

The organization must learn to deal with the current pretences caused by the speed of the Quality driven transformation, where the informational flux is a vital element. To sustain such a perspective is possible through. designing the flexible organizational structures to facilitate the communication and to raise the accountability

The necessity the new, flexible structure is essential. To maintain the traditional structures leads, on short term, to failure in solving both the current and strategic problems. Through this perspective we notice some of the most significant landmarks of the new organizational form, which reflects the imperatives of the Quality strategy.

a. Decentralization of the structures - the dynamics of cooperation with all the actors of the meta-organization could lead to structures' changes;

b. Flattening of the structures - the communication process is almost paralyzed when it follows the hierarchical path; this wins, however, in efficacy when it follows the succession client - provider, already created by the processes.;

c. The structure in inter-disciplinary teams - this structural characteristic creates the transversal solution and represents the better solution when compared to: 1) the traditional structures becoming obsolete; 2) the large amount of information presently existing; 3) the failure of hierarchies. Although they comprise employees at all levels, equality exists inside the interdisciplinary teams due to the commonly shared information. Besides, each member of the team is in its centre, and the private objectives are easily integrated, while the motivations grew stronger.

\subsection{Re-vitalizing the portfolio of the organization}

Compared to the present challenges coming from communities, the traditional organizations in the public sector neglect almost completely the definition of future evolution, being mainly concerned with the adoption of defensive positions in order to minimize loss.

Long-term growth is possible through revitalization of the portfolio, a complex strategic approach focused on the way provided services are defined and dealt with.

\subsubsection{The focus on public interest}

Revitalizing the portfolio in the context of innovation through quality imposes a new managerial vision on the portfolio, the one of starting point in projecting future products / services of the organization.

The focus on public interest, vital to the achievement of the exceptional, is the result of coincidence between the distinct components or strengths of the organization and the satisfaction of the public interest defined by the requests of all the actors' component of the meta-organization. Obviously, this coincidence is not accidental.

The essence of this focusing lies in the examination of the relationships at the level of the meta-organization from the point of view of the public interest.

First of all, this reflects in the identification of the exigency criteria of the actors within the meta-organization (and not in what the management of the organization considers necessary) and, secondly, in the decision regarding the way the offer will satisfy this request efficiently and effectively. 
The actors' behavior is influenced by a series of factors which vary from one type of service to another. Knowing and anticipating these variations imposes limitation of the managerial orientations only to those strategic segments where actors' expectations and present and potential abilities of the organization concur.

The segmentation standard taken into account in this transformation was that of the homogeneity of the expected benefits and the price at which these benefits are obtained. The factors that express the public interest are bearers of some messages whose significance can be revealed only through direct involvement and attendance of the actors of the meta-organization.

\subsubsection{The invention of new public services}

The ways of achieving this exigency are presented in the following lines:

a. Development of the organizational competences. This process becomes a priority in answering to messages sent by the actors of the meta-organization (representatives of the public interest). Basic competences are represented by those abilities, capacities and technologies that define the specificity of the organization. Their identification, development and combination create new opportunities of satisfying the public interest. In these circumstances, the responsibility of the management id different regarding both the development of the basic competences and constructing and maintaining a motivational environment where creativity is encouraged. The focus on the basic competences of the organization facilitates expansion towards other services than the traditional ones.

b. Building alliances / partnerships. Alliances/partnerships are the way to the selective revitalization of the services based on new competences resulted from the combination between the abilities and capacities of the companies that compose the alliance.

The simplest form of alliance is the opportunist alliance. This type of alliance is determined by two factors: technological progress and market globalization. The need imposed by the conditions of the competitiveness, to align to the technological innovation forces organizations to look for alliances with creative partners, offering their position on the market in exchange for access to innovation.

The motivations of the opportunist alliances are very simple: cost reduction, know-how acquisition and risk sharing. Thus, the role of the management of the organization is decisive in building an alliance. In this case, the significant managerial challenge is giving up borders and supporting free knowledge and ability exchange in the interest of the alliance.

Contrary, however attractive the strategic project of the alliance is, it will fail. At the other end from the opportunist alliance, alliances can represent the emergence to a new economic order where businesses are the knots of a network and the managerial ability and efficiency of the network are the clues of the success. The essence of network creation is collaboration based on the complementary principle. The nature of the collaboration within the network is so well defined that the independence and interests of the individual businesses are not affected.

\subsubsection{Redefining public services through technology}

Using technology to extend or re-define the portfolio of the services provided is the biggest challenge of the revitalization. 
Although nowadays the number of the organizations that succeeded in overcoming these challenges is small, in the following decades it will go up because of the technological boom that will influence the rules of the game. The technological involvement in the way public services organizations operate starts with the increase of complexity requests for isolated activities and continues with connection and integration of tasks and processes, creation of internal networks and global redefinition of the public services offer.

Technological advantages imply: integration of processes through technology, involvement of technology in process reengineering, involvement of technology in network design. The informational technology next to consumers' needs and organizational abilities form the triad of events that when they are combined create opportunities for revitalization.

Technology links the actors of the meta-organization and its different departments facilitating common progress and improving speed and efficiency in finality achievement.

One of the most important technological applications is its strategic contribution to gathering and developing knowledge and to the acceleration of their dissemination within the meta-organization.

\subsection{Re-inventing the mentalities of the actors}

At the center of the Quality cycle lays the human aspect (see figure 4). No activity can be carried out effectively if the people involved are not willing to cooperate.

In order to do so, they have to be convinced that what they are asked to do is for their own benefit, rather than for another person or group of persons, be it the stakeholders or the customers.

\subsubsection{The new quality culture}

In order to achieve the strategic quality approach, an organization has to change. This change goes far beyond altering a method or modification of a process. It is, at first, a change in culture that is required; all other major changes will then follow from that.

Generally, culture represents the way through which the members of a group communicate, both among themselves and with other groups within the company. In the context of the communication process there are highlighted common behaviors, customs, practices, values and beliefs.

The new quality culture is characterized by the expanding of empowerment within the organization, on the basis of the market-in concept, by which the customer concept is introduced inside the public organization; thus, the public servants become binders of the institution, each of them knowing who he works for and knowing that person's exigencies, things which contribute to the creation and preservation of the customer cult in the entire public organization.

The culture is a vision of the future and a set of mostly unwritten values. It is partly inherited, partly effected by all actors who exercise an influence on and in the organization (J. Kelada, p.187). 
Ideally, actors of the meta-organization all share the same long-term global vision of the organization and of the environment in which they have to live and thrive. Consequently, every action they take will be inspired by and geared to this vision.

Culture is not a static concept or reality; it evolves with time and changes, often gradually but sometimes noticeably and abruptly. Cultural changes result from a constant feedback whether formal or informal conscious or unconscious - from the results of the culture (J. Kelada, p.189).

The importance of the new quality culture, articulated around transforming the mentality, consists, especially, of the implications due to it upon putting into practice the changing project. In other words, the success of changing the organizational culture depends on the total involvement of the public management, carefully focused on the institution's clients, but also on the public servants.

\subsubsection{A new style of management - The Total Quality Management}

TQM is principally based on a managerial philosophy, a way of thinking from which emanates a way of doing that is assumed by all persons in the organization as well by its external partners. This philosophy is customer focused, people centered, partner assisted, and environmentally conscious.

The Total Quality Management is an approach through which the organization makes sure that its processes, products, and services contribute to the achievement of clearly defined results. This managerial approach is mainly characterized by:

- Encouragement of stakeholders' participation;

- Realistic definition of expected changes or results;

- Selection of performance indicators;

- Risk assessment;

- Gathering information about performance;

- Using this information in the decision-making process;

- Relation to performance.

Based on the quality strategic approach, TQM has three dimensions: (1) the human dimension: political and psychological; (2) a logical dimension: rational and systematic: and (3) a technological dimension: mechanical and systematic. There are opinions through scholars that the first is the most important (J. Kelada,, p.57).

The human aspect has two objectives: to start and to maintain a quality process in the metaorganization. Indeed, top managers must be convinced that they have to change their ways of doing public business; they have to exercise strong leadership inside the organization with their people and outside with the external actor of meta-organization, both of whom they have to mobilize.

They have to "walk their talk", practice what they preach, be committed and involved. Then, once the strategic quality approach is under way, they have to continuously reinforce it by their attitude and behavior, by rewards and recognition, by participation and teamwork. The new public managers must not only acquire innovative and creative abilities necessary to define new horizons rapidly, but also facilitate their putting into practice. 
In this context, the contribution to behavioral re-orientation of organizational actors towards environmental changes is one of the vectors of the new managerial orientations.

The challenges of the current institutional climate are, in my opinion, generated not so much by the lack of knowledge of the rules of the game, but mostly by their continuous changing. The new managers in the public sector must not only rapidly accumulate innovative and creative capabilities necessary for defining certain new horizons, but also to facilitate their transposing into practice.

In this context, the contribution to the behavioral reorientation of the public servants in accordance with the environmental changes is one of the strategic vectors of the current managerial approach. In terms of consequences, it is necessary to give up the old paradigms and the total commitment, in spirit and in action, in a changing process defined on the long term, in the sense of the new public management exigencies.

\subsubsection{Building a continuous learning system}

The learning system represents the most advanced way of renewing the mentalities of the public organization's members. The promotion of this system implies the undertaking by the public organizations' managers of a double responsibility: (1) acknowledging the employees' individual needs for personal and professional development and (2) creating opportunities for satisfying these needs. The professionalism of public institutions has a rising dynamics, directly proportional to the number of public servants who continuously redefine their roles and responsibilities on the basis of the permanent improvement and adaptation of the public activities.

However, there are numerous examples of public organizations that ignore, willingly or out of a misunderstanding, this unlimited potential offered by each employee. Even more, the current circumstances indicate that, while bureaucracy is expanding its dimensions and complexity, the construction of a learning system becomes impossible. The reason at the foundation of this statement is argued further.

Firstly, those who represent the existing paradigms do not have the availability necessary for understanding the need for change and, implicitly, they are refractory to anything that takes them further from the "old road".

Secondly, every bureaucrat's mission is defined in terms of self-sufficiency and selfcommitment; this signifies the absence of the collective contacts, lateral or that cross the organization. The adopting of certain decisions and executive dispositions in this sense would not have the benefic effects taken into account because the majority of the factors involved in the decisional process are the representatives of the old paradigms.

\section{Conclusion}

Accordingly, we think that the metaorganization built corresponds to the exigence imposeed by sector IV of figure 6. It integrates co-production and co-evaluation, but adds also co-design and co-decision. These two crucial participative steps are only possible if there is a combined external and open orientation with a focus on outputs and outcomes. This results in co-governing. ${ }^{7}$

7 C., Pollitt, G.,.Bouckaert, E.,Loffler, Making Quality Sustainable: Co-Design, Co-Decide, Co-Produce, and Co-Evaluate, The 4QC Conference, Tampere, 2006., p. 18. 


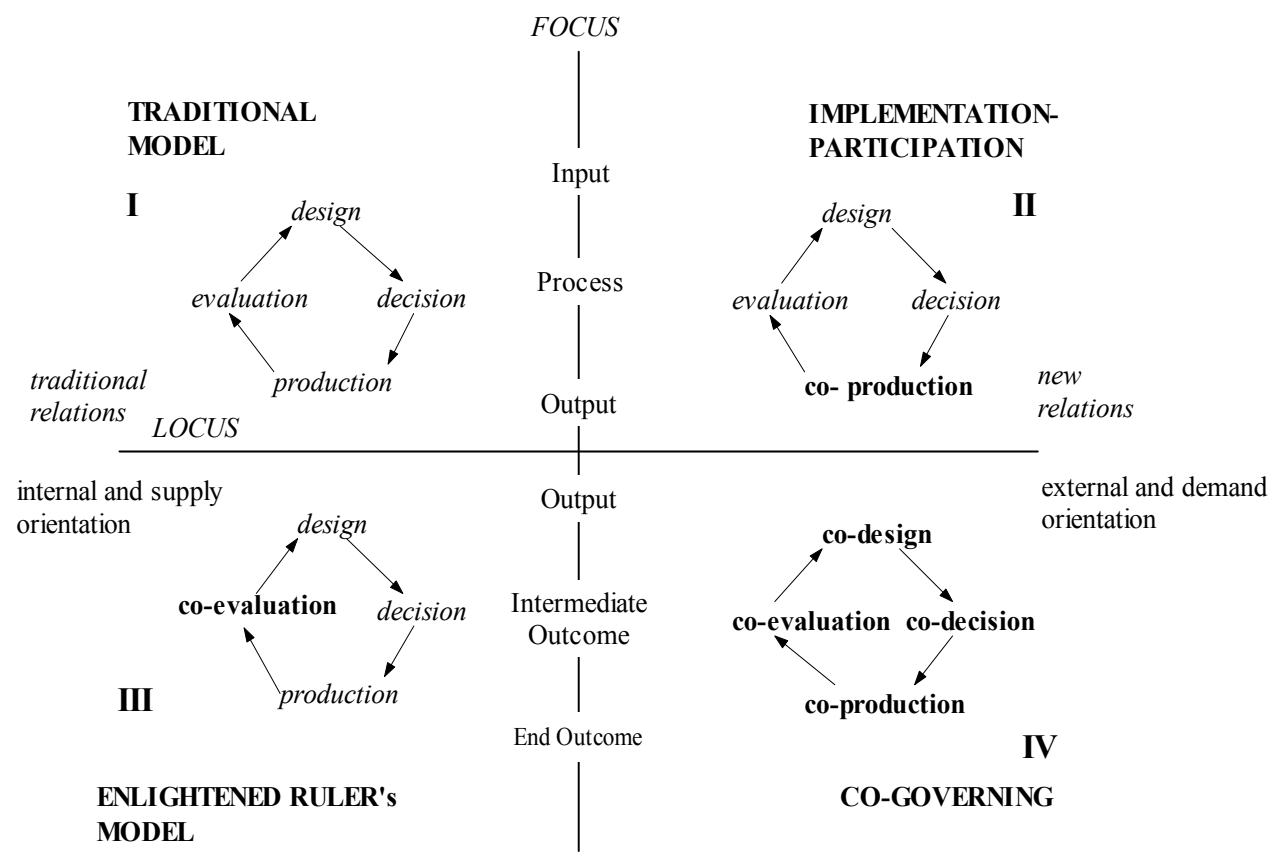

Fig. 6. Models for sustainability in the public sector Sursa: C., Pollitt and G.,Bouckaert, Quality Improvement in European Public Services, 1995, p.163

There are three important aspects in the governance of complex public sector networks. The first aspect is the context- defined as the environment. Second is the complexity - defined as the number and variety of the system's elements and the relations between the system elements. The third aspect is governance- defined as directed influencing.

In a network of many separate actors, with different and often conflicting goals and interests and with diverging power positions, no single dominant actor exists. Such complexity means negotiation and implies a different form of governance than mono-centric, mono-rational, hierarchical top-down control by an omnipotent government. On the other hand, public governance in complex network differs from the polar opposite of hierarchy, total autonomy of actors. Networks are characterized by many dependencies and relationships among the actors.

The distinction between a multi-actor network and completely autonomous actors is not without meaning. It means that actors not entirely independent and it also means that although actors are not hierarchically sub-or super-ordinate, they are not completely equivalent. Government will always take a different position than other societal public and private actors in a network. Government cannot dominate and unilaterally dictate but nevertheless, it is not entirely equivalent to all other actors. This is not a normative statement but an empirical observation than the role of government in networks is special and unlike the roles of many other actors. This does not imply a return to top-down control. It does imply that full horizontality and total autonomy of actors is an unrealistic model of a public policy network. 
Network governance concept lies somewhere in the grey area between both extremes of hierarchy and market. It is remarkable that the few people interest ed in developing the public sector-oriented approach all emphasize the importance of public governance for public management and public organization.

\section{References}

Ansoff, I., E. McDonneell, 1990, Implanting Strategic Management, Prentice Hall, New York ;

Drucker, P, 2000, . Post capitalist Society, ed. Image, Bucharest

Fukuyama, F., 2004, State -Building. Governance and World Order in the 21st Century, Ed. Antet XX Press, Bucharest

Gelinier, O. 1990, Stratégie de lentreprise et motivation des hommes, Ed. Hommes et Techniques, Paris

Gilles, P., 1994, New Patterns of Governance, Kenneth Press, Ottawa;

Guskin, A., 1994, Part II: Restructuring the Role of the Faculty, Change 26, no.5: 16-25.;

Hammer, M. J.,Champy ,1996, Reeingineering of Enterprise, ed. Tehnică, București

Harvey L., 2000, New Realities: The Relationship between Higher Education and Employment, Source: Tertiary Education and Management ;

Harvey, L., Knight, P.T., 1996, Transforming Higher Education., Buckingham: Society for Research into Higher Education (SRHE) and Open University Press;

Harvey, L., Moon, S.,Geall, VGraduates, 1997, Organizational Change and Students' Attributes., Birmingham: Centre for Research into Quality (CRQ) and Association of Graduate Recruiters (AGR)

J Taylor 2003, Institutional Diversity in UK Higher Education: Policy and Outcomes Since the End of the Binary Divide - Higher Education Quarterly, - Wiley Online Library

Lomas, L. , 2007, Zen, motorcycle maintenance and quality in higher education, Quality Assurance in Education, Volume 15 No 4, pp402-412

Morgan, G, 1989, Creative Organization Theory, Newbury park, California, Sage Publication;

Pirsig, Robert M. , 1974, Zen and the Art of Motorcycle Maintenance - An Inquiry into Values, Boadly Head, UK.

Politt C., and G., Bouckaert, 1995, Quality Improvement in European Public Services, SAGE Publication Ltd. London

Pollitt, C., G.,.Bouckaert, E.,Loffler, 2006, Making Quality Sustainable: Co-Design, Co-Decide, Co-Produce, and Co-Evaluate, Report of The 4QC Conference, Tampere

Popescu, L.G. 2007, The innovation of the public services by quality strategic approach, Transylvanian Review of Administrative Sciences nr.19(E).

Popescu, L.G., 2005, The company managed by Total Quality, International Conference RaDMI, , Belgrad, pp. 230-238.

Popescu, L.G., 2011, Institutionalization of Strategic Responsiveness in Higher Education, Report of The ISQM Conference, Sibiu

Stein, F.R. 1999, The next phase of Total Quality Management, Marcel Dekker Inc., New York Teece J.D., 2009, Dynamic, Capabilities and Strategic Management, Oxford University Press Woodhouse, David, Introduction to Quality Assurance, 2009, AUQA 


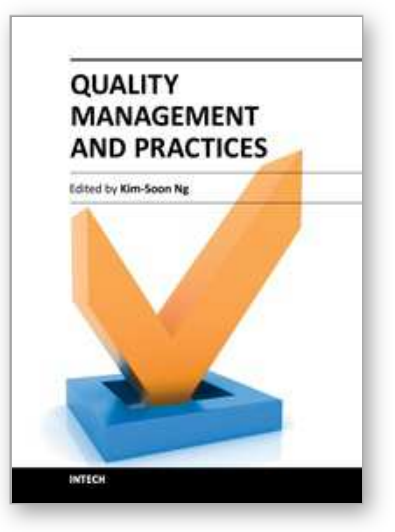

\author{
Quality Management and Practices \\ Edited by Dr. Kim-Soon Ng
}

ISBN 978-953-51-0550-3

Hard cover, 254 pages

Publisher InTech

Published online 27, April, 2012

Published in print edition April, 2012

This book is comprised of a collection of reviews and research works from international professionals from various parts of the world. A practical approach to quality management provides the reader with the understanding of basic to total quality practices in organizations, reflecting a systematic coverage of topics. Its main focus is on quality management practices in organization and dealing with specific total quality practices to quality management systems. It is intended for use as a reference at the universities, colleges, corporate organizations, and for individuals who want to know more about total quality practices. The works in this book will be a helpful and useful guide to practitioners seeking to understand and use the appropriate approaches to implement total quality.

\title{
How to reference
}

In order to correctly reference this scholarly work, feel free to copy and paste the following:

Luminita Gabriela Popescu (2012). The Strategic Approach of Total Quality and Their Effects on the Public Organization, Quality Management and Practices, Dr. Kim-Soon Ng (Ed.), ISBN: 978-953-51-0550-3, InTech, Available from: http://www.intechopen.com/books/quality-management-and-practices/the-strategic-approachof-total-quality-and-their-effects-on-the-public-organization

\section{INTECH}

open science | open minds

\section{InTech Europe}

University Campus STeP Ri

Slavka Krautzeka 83/A

51000 Rijeka, Croatia

Phone: +385 (51) 770447

Fax: +385 (51) 686166

www.intechopen.com

\section{InTech China}

Unit 405, Office Block, Hotel Equatorial Shanghai

No.65, Yan An Road (West), Shanghai, 200040, China

中国上海市延安西路65号上海国际贵都大饭店办公楼405单元

Phone: +86-21-62489820

Fax: +86-21-62489821 
(C) 2012 The Author(s). Licensee IntechOpen. This is an open access article distributed under the terms of the Creative Commons Attribution 3.0 License, which permits unrestricted use, distribution, and reproduction in any medium, provided the original work is properly cited. 